João O. Malva, Ana P. Vieira and Catarina R. Oliveira

Advan Physiol Educ 27:78-85, 2003. doi:10.1152/advan.00053.2002

You might find this additional information useful...

Medline items on this article's topics can be found at http://highwire.stanford.edu/lists/artbytopic.dtl on the following topics:

Cell Biology .. Glutamate Receptors

Oncology ... AMPA Receptors

Neuroscience .. Glutamate

Neuroscience .. Neurotransmitters

Medicine .. Microscopy

Medicine .. Medical Students

Updated information and services including high-resolution figures, can be found at:

http://ajpadvan.physiology.org/cgi/content/full/27/2/78

Additional material and information about Advances in Physiology Education can be found at: http://www.the-aps.org/publications/advan

This information is current as of March 2, 2010 .

Advances in Physiology Education is dedicated to the improvement of teaching and learning physiology, both in specialized courses and in the broader context of general biology education. It is published four times a year in March, June, September and December by the American Physiological Society, 9650 Rockville Pike, Bethesda MD 20814-3991. Copyright () 2005 by the American Physiological Society. ISSN: 1043-4046, ESSN: 1522-1229. Visit our website at http://www.the-aps.org/. 


\title{
UNDERSTANDING THE PHYSIOLOGY OF GLUTAMATE RECEPTORS BY USE OF A PROTOCOL FOR NEURONAL STAINING
}

\author{
João O. Malva, Ana P. Vieira, and Catarina R. Oliveira \\ Center for Neuroscience and Cell Biology of Coimbra, Institute of Biochemistry, Faculty of Medicine, \\ University of Coimbra, 3004-504 Coimbra, Portugal
}

eaching students about the physiology of neurotransmitter receptors usually
requires practical lessons with the use of sophisticated equipment and
complex analysis of data. Here, we report our experience in teaching medical students with a simple, practical protocol that transforms the physiology of glutamate receptors into neuronal staining, observable under bright-field microscopy. Essentially, the students were challenged to selectively stain a subpopulation of cultured neurons expressing $\mathrm{Ca}^{2+}$-permeable $\alpha$-amino-3-hydroxy-5-methylisoxazole-4-propionate (AMPA) receptors (a subgroup of ionotropic glutamate receptors). Neurons expressing this type of receptors were loaded with $\mathrm{Co}^{2+}$ (in substitution for $\mathrm{Ca}^{2+}$ ) after nondesensitizing activation of AMPA receptors. After precipitation, the $\mathrm{Co}^{2+}$ was revealed after treatment with silver. At the end of the procedure, the neurons expressing $\mathrm{Ca}^{2+}$-permeable AMPA receptors were visually identified under brightfield microscopy. The procedure allowed the visualization of the complete dendritic network of the stained neurons and allowed the students to learn very efficiently about the physiology of glutamate receptors.

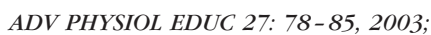

Key words: neurons; cobalt staining; $\alpha$-amino-3-hydroxy-5-methylisoxazole-4-propionate receptors; neurotransmitters

The program of Medical Biology at our university includes the study of messengers in intercellular and intracellular communication. It is our experience that one of the major challenges in practical teaching is the application of abstract concepts in simple and direct practical lessons. Using cultured rat hippocampal neurons, we implemented a practical protocol aimed at letting the students understand, through direct experiences, that nondesensitizing stimulation of $\alpha$-amino-3-hydroxy-5-methylisoxazole-4-propionate (AMPA) receptors causes the influx of cations, including $\mathrm{Co}^{2+}$, when they are added to the extracellular medium. The accumulation of $\mathrm{Co}^{2+}$ in the cytoplasm of a neuronal subpopulation may then be used for neuronal staining. The strategy was to allow the students to transform abstract concepts from the molecular level into visible phenomena at the cellular level, observable under bright-field microscopy.

We briefly transmitted to the student some key information for the understanding of the objectives of the proposed work.

Neurotransmitters are the key players of neuronal physiology. At the synapse, the presynaptic element releases neurotransmitters that interact with postsynaptic receptors, allowing the transmission of the neuronal signal. Among the various neurotransmitters, 
glutamate is especially important, because it is the principal excitatory neurotransmitter in the mammalian brain and it plays a critical role in the physiology and dysfunction of the nervous tissue. After the release of glutamate into the synaptic cleft, it can activate glutamate receptors either presynaptically (acting as modulators) or postsynaptically (as postsynaptic modulators or involved in the synaptic transmission). Glutamate receptors can be coupled to the activation of intracellular $G$ proteins and production of second messengers-metabotropic receptors (9) - or they may allow the influx of cations through a receptor-associated channel, causing membrane depolarization-ionotropic receptors $(4,7)$. Among ionotropic glutamate receptors, $N$-methyl-D-aspartate (NMDA) receptors are efficiently activated by NMDA and are highly permeable to $\mathrm{Ca}^{2+}$, whereas nonNMDA receptors (AMPA and kainate receptors) are not efficiently activated by NMDA but are efficiently activated by AMPA or kainate (2). Among glutamate receptors, the NMDA receptors are the subtype with the highest permeability to divalent cations. However, some AMPA receptors may also be especially permeable to $\mathrm{Ca}^{2+}$ (4) following activation of the receptor with the endogenous neurotransmitter glutamate or by exogenously adding receptor agonists (e.g., AMPA). The protocols proposed in the present work take advantage of the $\mathrm{Ca}^{2+}$ permeability of some AMPA receptors and allow the selective staining of a subpopulation of cultured rat hippocampal neurons.

We expected that, at the end, the students would be able to 1) understand some of the basic mechanisms of the physiology of the neurotransmitter glutamate; 2) understand why it is possible to selectively stain a subpopulation of neurons expressing $\mathrm{Ca}^{2+}$-permeable AMPA receptors; and 3) know how to prepare highquality neuronal preparations useful for observing the complete morphology of hippocampal neurons.

\section{METHODS}

Students. Students in six different classes of the Medical Biology course at our faculty were grouped in five groups of four students. The students were given a handout on the practical protocol and on the theoretical basis of the experiment (as mentioned above). The students were informed that the protocol was prepared for two different classes $(2 \mathrm{~h}$ and $30 \mathrm{~min}$ each). On the 1st day, the protocol must proceed until the end of the fixation step, and it must terminate on the 2 nd day (1 wk later).

Chemicals. Neurobasal medium, B27 supplement, gentamicin, and trypsin (USP grade) were purchased from GIBCO-BRL (Paisley, Scotland, UK). Glutamate, deoxyribonuclease (DN-25), and mouse anti-rat microtubule-associated protein-2 (MAP2) were purchased from Sigma Chemical (St. Louis, MO). AMPA, cyclothiazide, and 6-cyano-7-nitroquinoxaline-2,3-dioxine (CNQX) were purchased from Tocris Cookson, (Bristol, UK). Goat anti-mouse IgG labeled with AlexaFluor 594 and Prolong Antifading were from Molecular Probes (Leiden, The Netherlands). All of the other reagents were from Sigma Chemical or Merck-VWR International (Darmstadt, Germany).

Neuronal cultures (prepared by the teacher). Rat embryos E18-E19 were obtained after a pregnant rat was killed by cervical dislocation under anesthesia. All of the procedures were in accord with the European guidelines for handling laboratory animals. The tutor was emphatic in transmitting to the students the requirement to be fair with animals and to reduce the animals' anxiety and suffering. Only experienced and qualified investigators are allowed to handle live animals.

In the tissue culture room, the skull of the embryo was opened, the brain was removed, and the hippocampus was dissected. Hippocampal neurons were dissociated after treatment with trypsin $(2.0 \mathrm{mg} / \mathrm{ml}$, $\left.15 \mathrm{~min}, 37^{\circ} \mathrm{C}\right)$ and deoxyribonuclease $\mathrm{I}(0.15 \mathrm{mg} / \mathrm{ml})$ in $\mathrm{Ca}^{2+}$ - and $\mathrm{Mg}^{2+}$-free Hanks' balanced salt solution (in $\mathrm{mM}: 137 \mathrm{NaCl}, 5.36 \mathrm{KCl}, 0.44 \mathrm{KH}_{2} \mathrm{PO}_{4}, 0.34$ $\mathrm{Na}_{2} \mathrm{HPO}_{4} \cdot 2 \mathrm{H}_{2} \mathrm{O}, 4.16 \mathrm{NaHCO}_{3}, 5$ glucose, 1 sodium pyruvate, $10 \mathrm{mM}$ HEPES, $\mathrm{pH}$ 7.4). After plating on poly-D-lysine-coated $(0.1 \mathrm{mg} / \mathrm{ml})$ glass coverslips at a density of $45 \times 10^{3}$ cells $/ \mathrm{cm}^{2}$, the cells were cultured in serum-free Neurobasal medium, supplemented with B27 supplement, glutamate $(25 \mu \mathrm{M})$, glutamine $(0.5 \mathrm{mM})$, and gentamicin $(0.12 \mathrm{mg} / \mathrm{ml})$, as described previously $(1,3)$. Cultures were kept at $37^{\circ} \mathrm{C}$ in a moist atmosphere of 5\% $\mathrm{CO}_{2}-95 \%$ air for 7- 8 days. For each group of four students, 16 coverslip were prepared. 
Cobalt staining. The cobalt staining procedure was performed essentially as previously described $(6,8)$, with some modifications now described.

The culture medium of the neuronal cultures (7-8 days) was removed, and cells were washed twice with HEPES buffer (in mM: $146 \mathrm{NaCl}, 4.2 \mathrm{KCl}, 0.5$ $\mathrm{MgCl}_{2}, 0.8 \mathrm{CaCl}_{2}, 55.6$ glucose, 20 HEPES, $\mathrm{pH} 7.4$ ) at $37^{\circ} \mathrm{C}$. After a washing, the cells were incubated with $5 \mathrm{mM} \mathrm{CoCl}_{2}$ in HEPES buffer. At this point, the cells were stimulated by $100 \mu \mathrm{M}$ AMPA for $30 \mathrm{~min}$ to activate AMPA receptors and allow the influx of $\mathrm{Co}^{2+}$ into the neurons.

Each group performed the following experimental conditions (in $1 \mathrm{ml}$ of HEPES buffer at $37^{\circ} \mathrm{C}$ ): control, without AMPA stimulation; activation of AMPA receptors in the presence of $100 \mu \mathrm{M}$ AMPA; activation of nondesensitizing AMPA receptors in the presence of $100 \mu \mathrm{M}$ AMPA plus $30 \mu \mathrm{M}$ cyclothiazide; inhibition of non-NMDA receptors in the presence of $100 \mu \mathrm{M}$ AMPA plus $30 \mu \mathrm{M}$ cyclothiazide plus $30 \mu \mathrm{M}$ CNQX; control in the presence of $30 \mu \mathrm{M}$ cyclothiazide.

After the stimulation period, the cells were washed twice with HEPES buffer supplemented with $2 \mathrm{mM}$ EDTA for 5 and $10 \mathrm{~min}$ to remove the excess of extracellular $\mathrm{Co}^{2+} . \mathrm{Co}^{2+}$ inside the neurons was precipitated by using HEPES buffer containing $0.12 \%$ $\mathrm{Na}_{2} \mathrm{~S}$ for $5 \mathrm{~min}$. After the precipitation period, the cells were washed once with HEPES buffer. The next step was the fixation of the cells by using phosphatebuffered saline (PBS; in $\mathrm{g} / \mathrm{l}: 8 \mathrm{NaCl}, 0.2 \mathrm{KCl}, 2.9$ $\left.\mathrm{Na}_{2} \mathrm{HPO}_{4} \cdot 12 \mathrm{H}_{2} \mathrm{O}, 0.2 \mathrm{KH}_{2} \mathrm{PO}_{4}, \mathrm{pH} 7.4\right)$ containing $4 \%$ paraformaldehyde and $4 \%$ sucrose for $30 \mathrm{~min}$ at room temperature. After the fixation period, the cells loaded with cobalt were visualized after development in the presence of $\mathrm{AgNO}_{3}$ and hydroquinone. The cells were washed with development solution (in mM: 292 sucrose, 15.5 hydroquinone, 42 citric acid) at $50^{\circ} \mathrm{C}$, and the development was performed in development solution containing $1 \mathrm{mg} / \mathrm{ml} \mathrm{AgNO}_{3}$, protected from the light, at $50^{\circ} \mathrm{C}$, for a period between $45 \mathrm{~min}$ and $1 \mathrm{~h}$ (visually inspected to evaluate the evolution of the development). When the $\mathrm{Co}^{2+}$-positive neurons appeared dark, the development was stopped by removing the solution containing the silver and washing once with warm development solution. The neurons were incubated with $5 \%$ sodium thiosulfate at room temperature for $10 \mathrm{~min}$ to remove excess $\mathrm{AgNO}_{3}$. Finally, the neurons were air dried and mounted with Entellan (Merck). The preparations were visualized under light microscopy.

Anti-MAP2 immunocytochemistry (not to be performed in the class). Neuronal cultures previously stained for $\mathrm{Co}^{2+}$ uptake were used for immunocytochemistry against the neuronal marker MAP2. The whole process was performed at room temperature. The cultures were washed twice $(10 \mathrm{~min})$ with PBS and treated with PBS containing 0.2\% Triton for 2 $\mathrm{min}$. After the treatment with the detergent, the cultures were washed three times ( 5 min each) with PBS, followed by incubation with PBS containing 3\% bovine serum albumin (BSA) for $30 \mathrm{~min}$ to block nonspecific binding of the antibodies. After blocking, the cultures were washed again three times with PBS (5 min each), followed by incubation with the primary antibody, mouse anti-rat MAP2 diluted 1:500 in PBS containing 3\% BSA for $1 \mathrm{~h}$. After treatment with the primary antibody, the cultures were again washed as previously. Treatment with the secondary antibody, goat anti-mouse IgG labeled with Alexa-Fluor 594 diluted 1:200 in PBS containing 3\% BSA, was performed for $1 \mathrm{~h}$ under light protection. The excess of antibody was removed by three-time PBS washing (as previously described), and the coverslips were mounted with Prolong Antifading. After being dried, the slides were stored at $-20^{\circ} \mathrm{C}$ and protected from light. The preparations were visualized under fluorescence microscopy (for anti-MAP2) and under bright-field microscopy (for cobalt uptake).

Safety procedures. Care must be used when preparing and using paraformaldehyde, $\mathrm{Na}_{2} \mathrm{~S}$, cobalt, and $\mathrm{AgNO}_{3}$. A safety cabinet must be used for storage. Only minimal amounts of these compounds should be prepared, and after use they must be disposed of as toxic waste according to the safety procedures of the laboratory.

\section{RESULTS}

Neurons in the control culture were not stained following the $\mathrm{Co}^{2+}$ uptake experiment (Fig. 1A). The accumulation of $\mathrm{Co}^{2+}$ inside the neurons depended on the nondesensitizing activation of non-NMDA glutamate receptors. Accordingly, in the presence of 100 

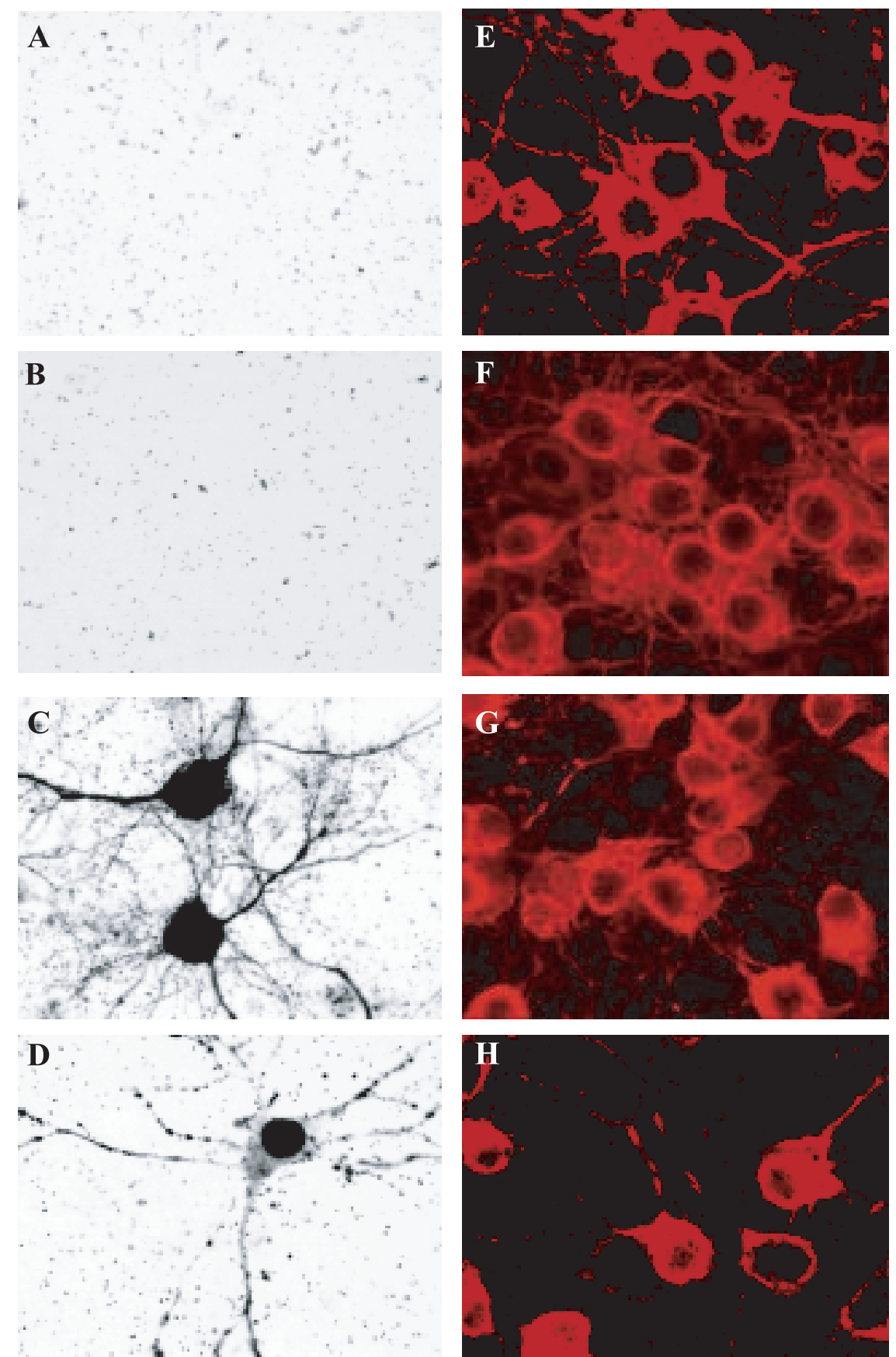

FIG. 1.

Imaging of cobalt uptake by cultured rat hippocampal neurons induced by activation of non- $N$-methyl-D-aspartate (NMDA) glutamate receptors (magnification $\times 500)$. Bright-field images of $\mathrm{Co}^{2+}$ uptake in control $(A)$ and following treatment with $100 \mu M \alpha$-amino-3-hydroxy-5-methylisoxazole-4-propionate (AMPA; B), 100 $\mu M$ AMPA $+30 \mu$ M cyclothiazide $(C)$, or $100 \mu$ M AMPA $+30 \mu$ M cyclothiazide +30 $\mu M$ 6-cyano-7-nitroquinoxaline-2,3-dioxine (CNQX; D). E-H : corresponding fields in $A-D$ but obtained under fluorescence microscopy after preparation was processed for anti-microtubule-associated protein-2 (MAP2) immunocytochemistry. 
$\mu \mathrm{M}$ AMPA, no evident $\mathrm{Co}^{2+}$ uptake was found (Fig. $1 B$ ), but in the presence of $100 \mu \mathrm{M}$ AMPA and $30 \mu \mathrm{M}$ cyclothiazide a strong neuronal staining was identified on a subpopulation of neurons (Fig. 1C). The students could also observe that, in the presence of the non-NMDA receptor antagonist CNQX $(30 \mu \mathrm{M})$, the influx of $\mathrm{Co}^{2+}$ was significantly reduced, only a few neurons with faint cobalt staining being obtained (Fig. 1D). The control experiment performed to evaluate the direct effect of cyclothiazide on the $\mathrm{Co}^{2+}$ staining showed that the addition of $30 \mu \mathrm{M}$ cyclothiazide alone was without effect (not shown). In this case, all the observed microscope fields were similar to the pictures representing the control condition (Fig. 1, $A$ and $E$ ).

As an example, we show a neuronal preparation that was further processed for the immunocytochemistry described in the protocol. The rationale for this optional experiment was to show that not all of the neurons in the culture contain $\mathrm{CO}^{2+}$-permeable AMPA receptors. The application of this experiment allowed the quantification of the neurons positive for $\mathrm{Co}^{2+}$ uptake in the different experimental conditions as a percentage of the total number of neurons (positive for MAP2) in the culture. After Figs. 1 and 2 are observed, it is possible to conclude that only a subpopulation of the cultured neurons express $\mathrm{Ca}^{2+}$. permeable AMPA receptors. The maximal staining was obtained following nondesensitizing activation of AMPA receptors that resulted in staining of $20.7 \pm$ $1.8 \%$ (total no. of 2,500 neurons counted, five different preparations) of the neurons in the culture (Fig. 1, $A-D$, are the same fields as in Fig. $1 E-H$, respectively).

\section{DISCUSSION}

This laboratory is designed to illustrate the following learning points.

Neurons dissociated from embryonic rat hippocampus can be maintained in culture; they survive and differentiate.

AMPA can activate ionotropic non-NMDA glutamate receptors (AMPA and kainate receptors). Only some AMPA receptors are permeable to $\mathrm{Co}^{2+}$ (6). Cyclothiazide inhibits the desensitization of AMPA receptors (5) and potentiates the influx of $\mathrm{Co}^{2+}$ in neurons expressing $\mathrm{Ca}^{2+}$-permeable AMPA receptors

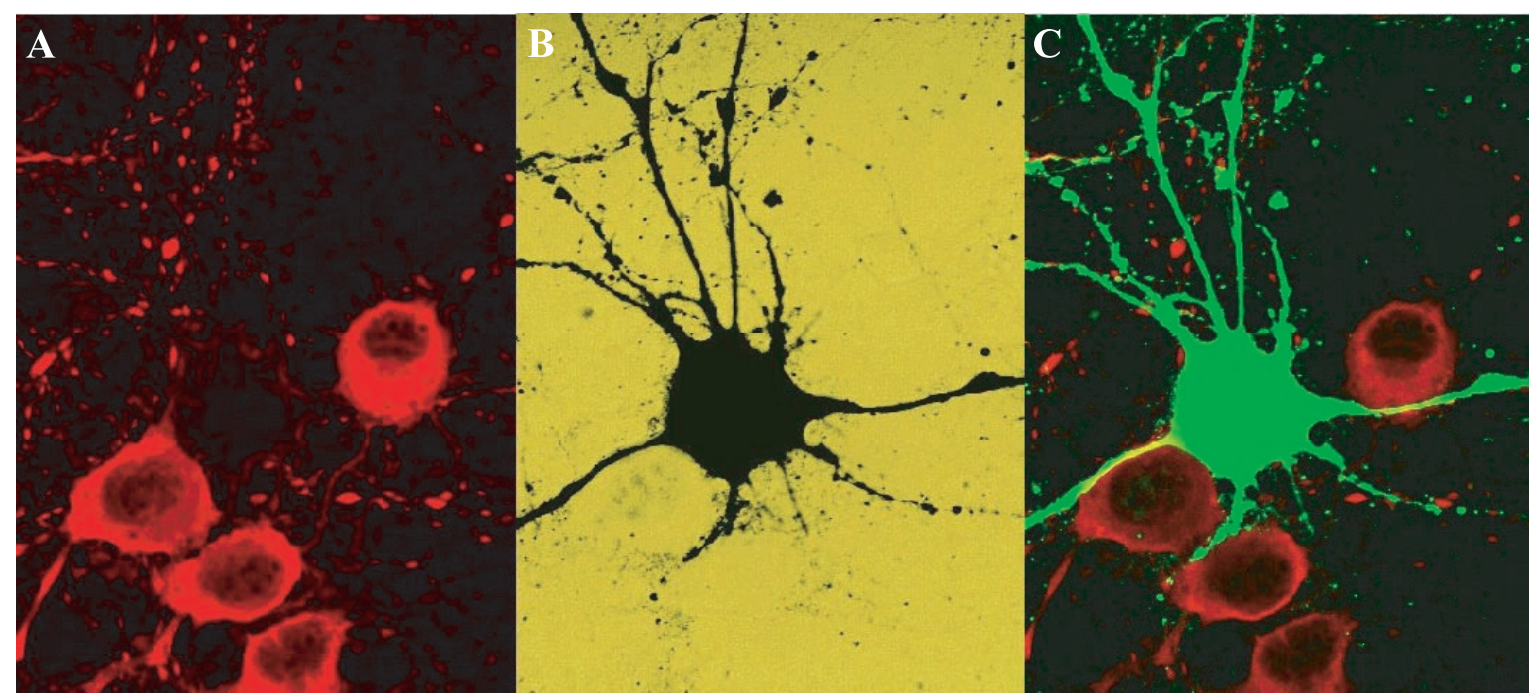

FIG. 2.

Imaging of cobalt uptake by cultured rat hippocampal neurons induced by activation of non-NMDA glutamate receptors by use of confocal microscopy (magnification $\times 1,000$ ). Culture was stimulated with $100 \mu M$ AMPA + $30 \mu \mathrm{M}$ cyclothiazide in the presence of $5 \mathrm{mM} \mathrm{CoCl}_{2}$, followed by immunocytochemistry treatment using anti-MAP2 as primary antibody. $A$ : confocal observation of anti-MAP2 labeling of hippocampal neurons. $B$ : bright-field observation of the same field as in $A$, demonstrating the presence of a $\mathrm{Co}^{2+}$-positive neuron. $C$ : overlay of images in $A$ and $B$, using a green pseudocolor for the $\mathrm{Co}^{2+}$-positive neuron. 
(Fig. 3). CNQX is a competitive antagonist of ionotropic non-NMDA glutamate receptors (2), and it is expected that, in its presence, fewer neurons accumulate $\mathrm{Co}^{2+}$. The inhibition of $\mathrm{Co}^{2+}$ staining is de- pendent on the concentration of both the agonist (AMPA) and the antagonist (CNQX). We performed an additional experiment with a lower concentration of CNQX $(10 \mu \mathrm{M})$ and, as expected, $100 \mu \mathrm{M}$ AMPA

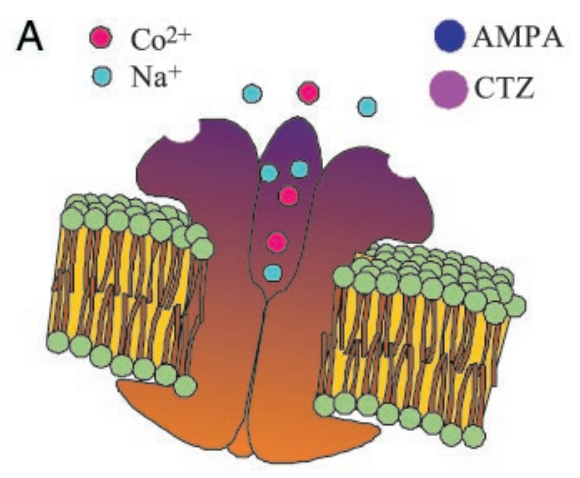

B
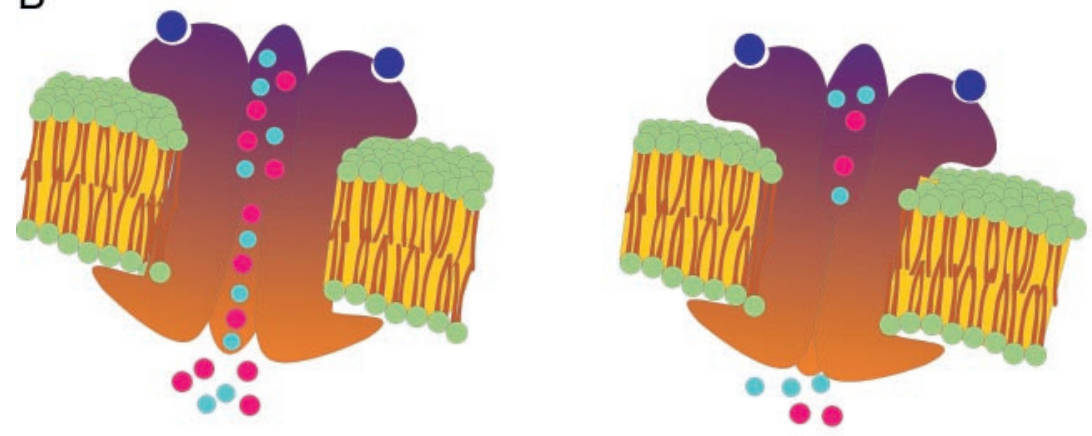

C
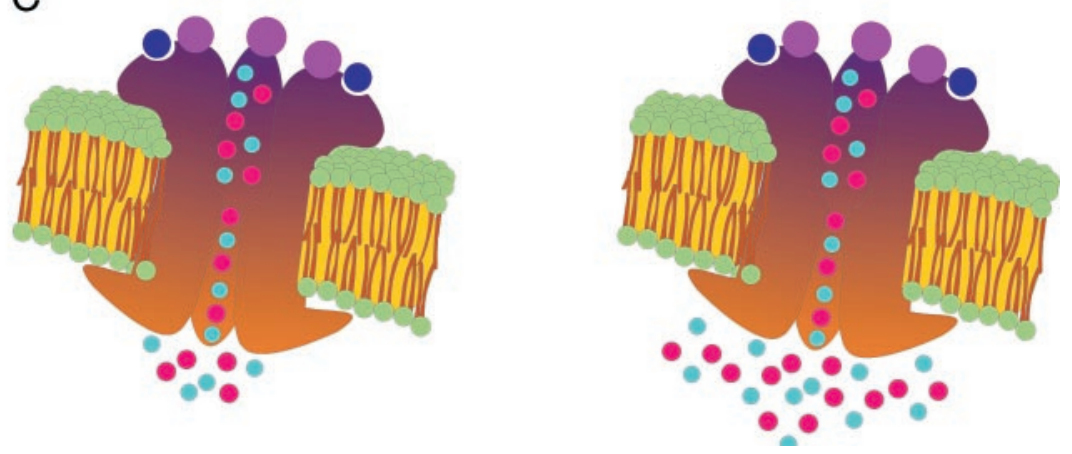

FIG. 3.

Schematic representation of the effect of $\mathrm{Ca}^{2+}$-permeable AMPA receptor desensitization [absence or presence of cyclothiazide (CTZ)] on the efficiency of $\mathrm{Co}^{2+}$ loading of cultured rat hippocampal neurons. $A$ : control, without stimulation. $B$ : activation under desensitizing conditions. $C$ : activation under nondesensitizing conditions (strong staining). 
plus $30 \mu \mathrm{M}$ cyclothiazide was less effective in inhibiting neuronal $\mathrm{Co}^{2+}$ staining (not shown).

After activation of $\mathrm{Ca}^{2+}$-permeable AMPA receptors in the presence of $\mathrm{Co}^{2+}$, the neurons were loaded with $\mathrm{Co}^{2+}$, which can be precipitated inside the neurons by using $\mathrm{Na}_{2} \mathrm{~S}$.

The precipitated $\mathrm{Co}^{2+}$ can be visualized by adding $\mathrm{AgNO}_{3}$, allowing the formation of cobalt-silver complexes. In the presence of hydroquinone, the silver is reduced to its metal state (dark), and the neurons containing the silver deposits can be visualized under light microscopy.

A

(1)

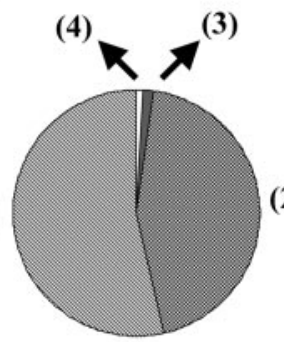

C

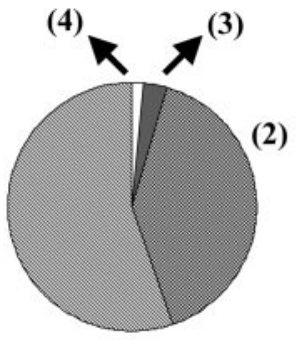

(1)
B

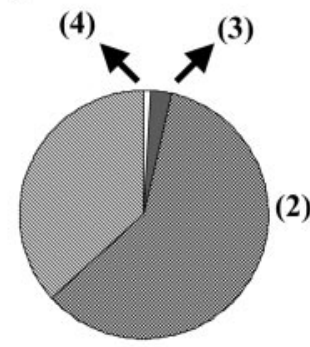

(1)

D

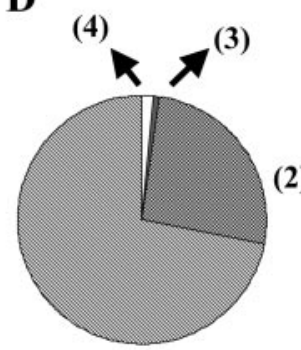

(1)
FIG. 4 .

Evaluation of proposed protocol by the students. An anonymous inquiry asking the student's opinion about 4 evaluating statements was performed. $A$ : "Concerning the proposed objectives the practical classroom was successfully developed;" $B$ : "The experiments were efficiently performed and understood;" $C$ : "The students enjoyed the practical procedure;" $D$ : "The practical class was appropriate for teaching Medical Biology." Students chose 1 of 4 possible answers: 1) completely agree; 2) agree; 3) do not agree; 4) do not agree absolutely. A total of 136 students participated in this inquiry. Question $A: 98 \%$ positive (1 and 2); question B: $96 \%$ positive (1 and 2); question C: $96 \%$ positive (1 and 2); question $D: 98 \%$ positive (1 and 2 ).
Neurons that did not accumulate cobalt were identified following immunocytochemistry using anti-MAP2 antibody (10). After performing the cobalt staining and the immunocytochemistry, the students could observe that only a subpopulation of hippocampal neurons express $\mathrm{Ca}^{2+}$-permeable AMPA receptors, and they could also quantify the number of neurons stained by $\mathrm{Co}^{2+}$ after the pharmacological manipulation of AMPA receptors.

In conclusion, the experiments proposed were successfully performed by the students despite their lack of background in neuroscience. The experiments were revealed to be very simple to implement, and the students were highly enthusiastic. Also, it was pleasant to observe that the scientific principles of the experiments were clearly understood by the group (Fig. 4).

The protocol was successful, through the practical teaching, in transmitting knowledge about the physiology of glutamate as a neurotransmitter and about the functional diversity of glutamate receptors. The quality of the stained neuronal preparations is strongly recommended for the visualization of intact and complete cultured hippocampal neurons. Moreover, we are convinced that the present work may be a good example of how good practical teaching can help young students overcome complex problems associated with abstract concepts.

We thank all the students involved in the Program Ciência Viva nas Férias at the Center for Neuroscience and Cell Biology of Coimbra (2000 and 2001) for their enthusiastic collaboration.

We acknowledge the support of the Unidade Ciência Viva, Ministério da Ciência e do Ensino Superior, Portugal. This work was also supported by Fundação para a Ciência e a Tecnologia, Portugal.

Address for reprint requests and other correspondence: J. O. Malva, Center for Neuroscience and Cell Biology of Coimbra, Institute of Biochemistry, Faculty of Medicine, Univ. of Coimbra, 3004-504 Coimbra, Portugal (E-mail: jomalva@cnc.cj.uc.pt).

Received 12 November 2002; accepted in final form 5 March 2003

\section{References}

1. Ambrósio AF, Silva AP, Malva JO, Mesquita JF, Carvalho AP, and Carvalho CM. Role of desensitization of AMPA receptors on the neuronal viability and on the $\left[\mathrm{Ca}^{2+}\right]_{\mathrm{i}}$ changes in cultured rat hippocampal neurons. Eur J Neurosci 12: 20212031, 2000. 
2. Bleakman D and Lodge D. Neuropharmacology of AMPA and kainate receptors. Neuropharmacology 37: 1187-1204, 1998.

3. Brewer GJ, Torricelli JR, Evege EK, and Price PJ. Optimized survival of hippocampal neurons in B27-supplemented Neurobasal $^{\mathrm{TM}}$, a new serum-free medium combination. $\mathrm{J} \mathrm{Neu}$ rosci Res 35: 567-576, 1993.

4. Dingledine R, Borges $\mathbf{K}$, Bowie $\mathbf{D}$, and Traynelis SF. The glutamate receptor ion channels. Physiol Rev 51: 7-61, 1999.

5. Hollmann $M$ and Heinemann S. Cloned glutamate receptors. Annu Rev Neurosci 17: 31-108, 1994.

6. Jensen B, Schousboe A, and Pickering DS. Development of calcium-permeable $\alpha$-amino-3-hydroxy-5-methyl-4-isoxazolepropionic acid receptors in cultured neocortical neurons visualized by cobalt staining. J Neurosci Res 54: 273-281, 1998.
7. Michaelis EK. Molecular biology of glutamate receptors in thecentral nervous system and their role in excitotoxicity, oxidative stress and aging. Prog Neurobiol 54: 369-415, 1998.

8. Pruss RM, Akeson RL, Racke MM, and Wilburn JL. Agonistactivated cobalt uptake identifies divalent cation-permeable kainate receptors on neurons and glial cells. Neuron 7: 509518, 1991.

9. Schoepp DD. Unveiling the functions of presynaptic metabotropic glutamate receptors in the central nervous system. J Pharmacol Exp Ther 299: 12-20, 2001.

10. Silva AP, Malva JO, Ambrósio AF, Salgado AJ, Carvalho AP, and Carvalho CM. Role of kainate receptor activation and desensitization on the $\left[\mathrm{Ca}^{2+}\right]_{\mathrm{i}}$ changes and neurotoxicity in cultured rat hippocampal neurons. J Neurosci Res 65: 378-386, 2001. 